\title{
Editorial
}

\section{Relating Systems Thinking and Design III}

This special issue of Form Akademisk captures some of the systemic design thinking and research presented at the RSD3 conference, held in Oslo, Norway in 2014, and the RSD4 conference, held in Banff, Canada in 2015. These two conferences offered a range of submissions encompassing the fields of design, systemics, public policy, healthcare, and other domains. This body of work explores the emerging renaissance of systems thinking in design. The papers presented here are responses to the world we live and design in, a world that is increasingly complex and increasingly problematic for those in government, industry and academia alike.

We believe that the thinking and intervention developed at RSD3 and RSD4 is well poised to meet these challenges. In this issue, we offer two sets of papers; the first set focuses on frameworks and organizing concepts, and the second set focuses on methods and tools to aid in systemic design.

\section{Articles in this issue}

We open the issue with Sevaldson's contribution, titled Redesigning Systems Thinking: Discussions on the Relation between Systemic Design and Aesthetics. This paper explores core concepts in design that are beneficial for systems thinking, including composition, choreography, orchestration, and the notion of the Gesamtkunstwerk. This paper takes an important step towards better synthesizing the work of systems thinking and the domain of design. Next, Ruttonsha's paper The Many Faces of Design: From Adaptive Response to Creative Agency to Emergent Engagement is presented. This work explores designers' relationships with complex adaptive systems, classifying these 'designerly ways' as adaptive, creative, and/or emergent. Together, these two papers provide useful prescription for designers and system developers dealing with complex systems.

Through case study and student exploration, the second set of papers provide a set of methods and tools for the systemic design community to leverage and adopt for their own work. Realizing the importance of teaching the next generation how to design for and work with complex systems, Da Costa's paper, titled Introducing systems oriented design for complex societal contexts in design engineering education explores using a systems approach in designing product-service systems in the context of a master's design studio course. Davidova's paper, titled Systemic Approach to Architectural Performance: The Media Mix in the Creative Design Process, presents a number of methods for working with complex digital and physical design spaces. Examples are selected from the author's doctoral study, and they extend existing methods, such as giga-mapping, into new problem areas and domains. These two papers reiterate the importance of building on existing research and methods in the community and to push the boundaries of how they are explored.

Three other submissions offer mindsets or concepts as starting points for engaging in systemic design. Ollove and Lteif's paper, titled Integrating Systems Thinking and Storytelling, explores the role of design in conflict resolution, offering a four step methodology based on story collection. It is clear that stories play a critical role in everything from therapy to legal testimony, and this paper shows that they occupy an important role in systemic design. AguirreUlloa and Paulsen's paper, titled Designing with Relationships in Mind, argues that a relational 
mindset is critical for the design of future products, services, and systems. A multi-sensory relational tool is presented to help understand social relationships through the use of material properties as materials for design. Barba's paper, titled Systemic Design for Second-Order Effects: A Case Study in Sustainability, presents a case study in which co-design methodology was used in designing a classroom intervention to create organizational change, and to control for its second order effects. Understanding the concept of second-order effects - unintended effects that come from first-order changes in a system - is a key component of systemic design. This set of papers offers educational materials for the design community beyond the classroom.

Through a collection of case studies and papers presenting organizing concepts and methods, this body of work collectively advances the field of systemic design. We hope you enjoy this issue.

Pittsburgh / Alberta / Oslo, June 2017

Jodi Forlizzi, Alex J. Ryan and Birger Sevaldson

Special Issue Editors

\section{Jodi Forlizzi}

Professor

Human-Computer Interaction Institute, School of Computer Science, Carnegie Mellon University

forlizzi@cs.cmu.edu

\section{Alex Ryan}

Co-Founder

Synthetikos Strategy Consulting

alex.ryan@gmail.com

\section{Birger Sevaldson}

\section{Professor}

Oslo School of Architecture and Design, Institute of Design

Email address: birger.sevaldson@aho.no 